\title{
DETERMINATION OF THE PRESENT VEGETATION STATE OF A WETLAND WITH UAV RGB IMAGERY
}

\author{
M. A. Boon ${ }^{\text {ab } *, ~ S . ~ T e s f a m i c h a e l ~}{ }^{\mathrm{c}}$ \\ a Department of Zoology University of Johannesburg, PO Box 524 Auckland Park, 2006, South Africa. \\ ${ }^{\mathrm{b}}$ Kite Aerial Imagery (Pty) Ltd, 1422 Topaas Street, Waverley, 0186, South Africa - boon@ live.co.za \\ ${ }^{c}$ Department of Geography, Environmental Management and Energy Studies University of Johannesburg, PO Box 524 Auckland \\ Park, 2006, South Africa - sgtesfamichael@uj.ac.za
}

KEY WORDS: wetland vegetation, aerial photography, UAV, 3D point clouds, DSM

\begin{abstract}
:
The compositional and structural characteristics of wetland vegetation play a vital role in the services that a wetland supplies. Apart from being important habitats, wetland vegetation also provide services such as flood attenuation and nutrient retention. South Africa is known to be a water scarce country. The protection and continuous monitoring of wetland ecosystems is therefore important. Factors such as site transformation and disturbance may completely change the vegetation of a wetland and the use of Unmanned Aerial Vehicle (UAV) imagery can play a valuable role in high-resolution monitoring and mapping. This study assessed if the use of UAV RGB imagery can enhance the determination of the present vegetation state of a wetland. The WET-Health level two (detailed on-site evaluation) methodology was followed for the vegetation assessment, where wetland health is a measure of the deviation of a wetland's structure and function from its natural reference condition. The mapping of the disturbances classes was then undertaken using ultra-high resolution orthophotos, point clouds and digital surface models (DSM). The WET-Health vegetation module completed with the aid of the UAV products still indicates that the vegetation of the wetland is largely modified ("D" PES Category) and that the vegetation of the wetland will further deteriorate (change score). These results are the same as determined in the baseline study. However a higher impact (activities taking place within the wetland) score were determined. The assessment of various WETHealth vegetation indicators were significantly enhanced using the UAV imagery and derived products. The UAV products provided an accurate vantage point over the wetland and surroundings, and assisted to easily refine the assessment of the disturbance classes and disturbance units.
\end{abstract}

\section{INTRODUCTION}

Remote sensing data have not been available at the appropriate scale until recently; UAVs can provide the appropriate spatial resolution needed by scientists (Zweig et al., 2015). Lucieer et al. (2013) specified that the "primary advantage of UAV-based remote sensing is the ability to bridge the scale gap between fieldbased observations and full-scale airborne or satellite observations". The ability of UAVs to fly low with capable sensors provides ecologists the opportunity to complete scaleappropriate measurements of ecological phenomena in fine spatial resolution (Anderson and Gaston, 2013).

Flener et al. (2012) characterized upland swamps using objectbased classification methods and hyper-spatial resolution imagery acquired using a UAV. The results of this study indicated that the combination of two new technologies (UAV and object-based image analysis (OBIA) methods can successfully classify swamp vegetation extents. Thamm et al. (2013) used a UAV to assess agricultural systems in a wetland in Tanzania in the wet and dry season over an area of $8 \mathrm{~km}^{2}$. A block bundle approach was used to compute the orthophotos and georeference the control points taken with a differential GPS. The orthophoto provided the possibility to assess the different land uses and the difference in phenology between the wet and the dry season. In a study by Zweig et al. (2015) the use of UAVs to delineate fine-scale wetland vegetation communities were assessed. This analysis was one of the first not to only acquire map or orthophoto but also data for fine-scale ecological community classification.
Marcaccio et al. (2015) also used UAVs to produce highresolution imagery to classify wetland vegetation and demonstrated that UAV photogrammetry provide the opportunity for researchers to easily obtain seasonally-relevant imagery themselves instead of using out-of-date commercial imagery. Husson et al. (2016) compared the manual mapping and automated object-based image analysis of non-submerged aquatic vegetation from very high resolution UAS images and found that it is feasible to extract ecologically relevant information on non-submerged aquatic vegetation from UASorthoimages in an automated way. Husson et al. (2017) found that combining spectral data with height data (DSM) has a great potential to increase the accuracy of automated classification of non-submerged aquatic vegetation.

In previous studies we showed that UAV derived orthophotos, point clouds and digital surface models (DSM) can significantly enhance wetland delineation, classification and health assessment trough the extraction of relevant information from these imagery (Boon et al., 2016a) and that these imagery can be used for rapid and accurate mapping of wetlands (Boon et al., 2016b). In this study we focused on wetland vegetation assessment (WET-Health) using UAV imagery.

\footnotetext{
* Corresponding author
} 


\subsection{Aim}

The aim of this study was to evaluate the performance of high resolution UAV imagery and derived products for enhancement of the WET-Health (Macfarlane et al., 2009) assessment of vegetation.

\section{STUDY AREA}

The channelled valley-bottom wetland (Fig. 1) is located on the Kameelzynkraal farm to the east of Pretoria in the Kungwini Local Municipal area, Gauteng Province, South Africa (Boon et al., 2016b).

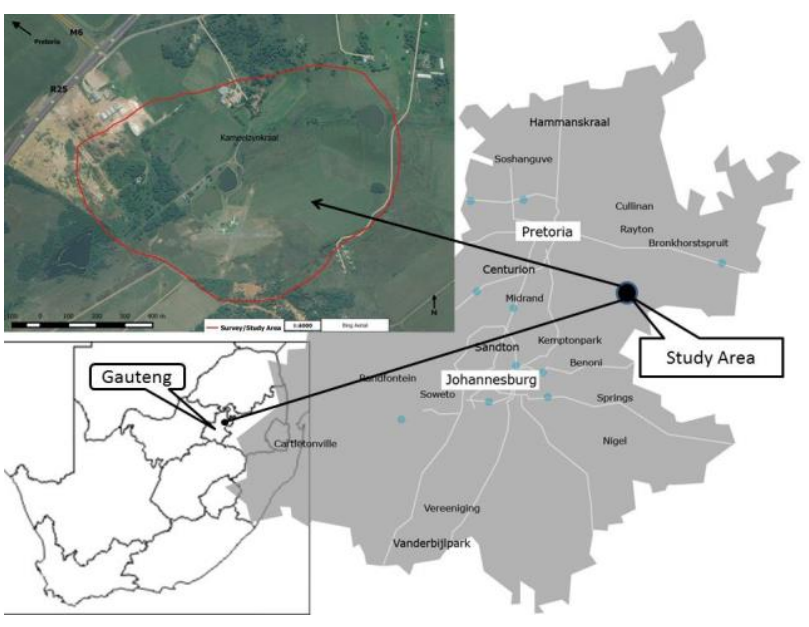

Figure 1. The Cors-Air study area to the east of Pretoria, Gauteng Province.

\section{MATERIALS AND METHODS}

The methodology can be divided into four phases indicated in Figure 2 and briefly discussed in sections 3.1 to 3.4 .

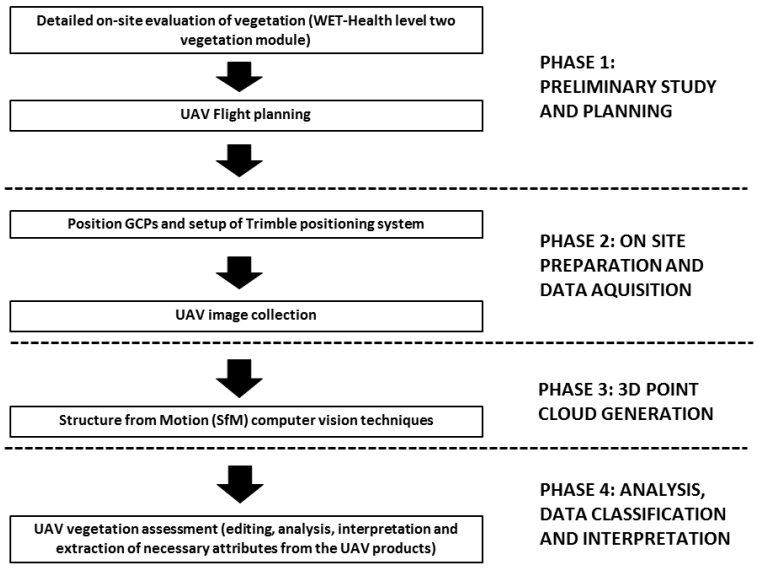

Figure 2. Flow diagram of methodology.

\subsection{Preliminary study and planning}

A detailed on-site and desktop evaluation of vegetation was completed using the level two WET-Health methodology (Macfarlane et al., 2009). This phase included calculation of study area, number of strips required, photo scale, flying height and percentage of overlapping and preparation of the final flight plan.
A 100ha UAV survey area was selected to include an functional wetland area of 15 ha (delineation extent) including the adjacent slopes in order to capture the landscape setting and impacts from the adjacent land uses More details on the WET-Health methodology used can be found in Boon et al. (2016a) and details on the flight planning and associated parameters in Boon et al. (2016b).

\subsection{On site preparation and data acquisition}

Ground control points (GCPs) were positioned across the site and at the boundaries of the UAV survey area using a Trimble (SPS985 GNSS GPS) site positioning system. An AKS Y-6 MKII multi-rotor UAV and the NIKON D3200 digital camera on a motion compensated gimbal mount were utilised for the collection of the images. Additional information on the GCP and UAV image collection including the UAV setup can be found in Boon et al. (2016b).

\subsection{D point cloud generation}

The completely automated computer vision Structure from Motion (SfM) pipeline provided by Agisoft PhotoScan Professional Version 1.1 commercial software package was used for the 3D point cloud generation. Boon et al. (2016b) describe the technical methodology followed in more detail. The results were exported in various formats including point clouds (ASPRS LAS), orthophotos (GeoTIFF, Google Earth KMZ) and DSMs (GeoTIFF elevation).

\subsection{Analysis, data classification and interpretation}

This step of the methodology includes editing, analysis, interpretation and extraction of necessary attributes from the UAV products. This was achieved through a combination of visual analysis of UAV orthophotos, DSMs and DPCs including extracting of information through the calculation of the intensity deviation of the DPCs (grid statistics calculation). Deviation is calculated for each grid cell by the following formula (Applied Imagery, 2015): $\left.\operatorname{SQRT}\left(\sum(x i-m) 2\right) / N\right)$ (where $x i$ is a variable sample, $\mathrm{m}$ is the sample mean for that grid cell, and $\mathrm{N}$ is the number of samples. The summation is from $\mathrm{i}=1$ to $\mathrm{i}=\mathrm{N}$ ). The calculations were applied to the point clouds in real time for visualisation. Table 1 indicate the WET-Health disturbance classes (activities taking place within the wetland) that have an impact on wetland vegetation that were assessed for both the detailed on-site evaluation of vegetation and the UAV vegetation assessment. More details on methods and tools used can be found in Boon et al. (2016a).

\begin{tabular}{|l|}
\hline VEGETATION DISTURBANCE CLASSES \\
\hline $\begin{array}{l}\text { 1. Identify and estimate the extent of each } \\
\text { disturbance class in the wetland }\end{array}$ \\
\hline Infrastructure \\
\hline Deep flooding by dams \\
\hline Annual pastures \\
\hline Dense alien vegetation patches. \\
\hline Shallow flooding by dams \\
\hline Sports fields \\
\hline Sediment deposition/ infilling and excavation \\
\hline Eroded areas \\
\hline Old / abandoned lands \\
\hline Seepage below dams \\
\hline Minimal human disturbance \\
\hline $\begin{array}{l}2 \\
\text { Assess the intensity and magnitude of impact } \\
\text { for each disturbance class }\end{array}$ \\
\hline
\end{tabular}

Table 1. Vegetation disturbance classes 


\section{RESULTS AND DISCUSSION}

The assessment of various WET-Health vegetation disturbance classes were significantly enhanced using the UAV imagery and derived products. The high resolution UAV imagery provided the opportunity to complete very fine scale extent determination and easy distinguish between the different disturbance classes. The assessment was further enhanced through three dimensional (3D) visualisation and interpretation of the UAV DSMs, including overlaying the orthophotos as a texture with the DSMs. Table 2 provides a summary of the products derived from the UAV imagery. The first column provides information about the root mean squared error (RMSE) and point densities obtained and the second colum the ground pixel resolution obtained for the orthophotos, dense point clouds (DPCs) and DSMs.

\begin{tabular}{|l|l|}
\hline Precision and sampling & UAV products \\
\hline $0.018 \mathrm{~m}$ overall RMSE & $\begin{array}{l}0.018 \text { and 0.025m ground } \\
\text { pixel resolution orthophoto } \\
\text { (wetland area) }\end{array}$ \\
\hline $0.0025 \mathrm{~m}$ vertical RMSE & $\begin{array}{l}0.05 \text { and 0.10m orthohpoto } \\
\text { (full extent) }\end{array}$ \\
\hline $\begin{array}{l}692.7 / \mathrm{m}^{2} \text { point density for } \\
\text { wetland area (high } \\
\text { reconstruction) }\end{array}$ & $\begin{array}{l}0.038 \mathrm{~m} \text { DPC and DSM } \\
\text { (wetland area) }\end{array}$ \\
\hline $\begin{array}{l}11.8 / \mathrm{m}^{2} \text { point density for } \\
\text { full extent (low } \\
\text { reconstruction) }\end{array}$ & $\begin{array}{l}0.29 \mathrm{~m} \text { DPC and DSM (full } \\
\text { extents) }\end{array}$ \\
\hline
\end{tabular}

Table 2. Summary of the UAV derived products

Information about infrastructure such as the internal roads, deep flooding by dams, areas of pasture and cultivation within and adjacent to the wetland as seen in Figure 2 was easily identified from the UAV orthophotos. Figure 3 presents information about deep flooding by dams (dam overgrown with Kikuyu grass), seepage below dams and the drains within the wetland (eroded areas).

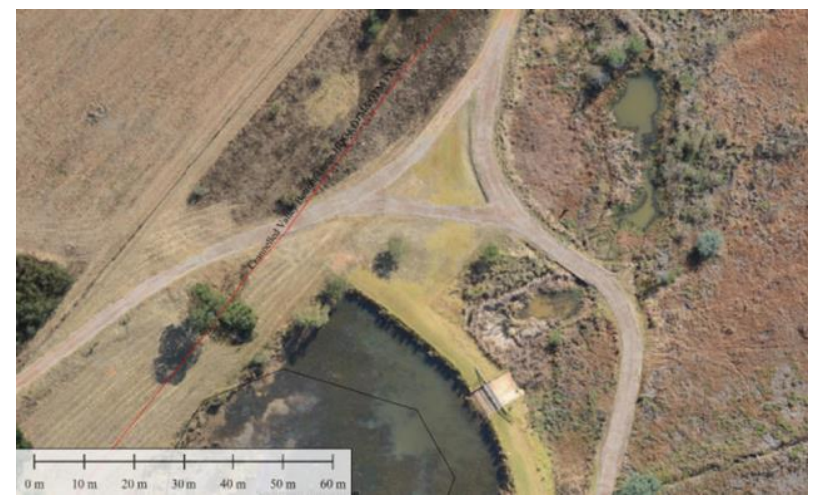

Figure 2. Estimation of disturbance classes from UAV orthophoto

The extent of small pockets of untransformed hydrophilic vegetation was determined (Figure 4) with some information from the field studies. This provided information on wetland areas with minimal human disturbance (limited disturbance). The determination of extent of alien woody plant types within and adjacent to the wetland was also possible, species such as the Black wattle (Acacia mearnsii) and Eucalyptus spp could be estimated. Trough further investigation areas of infestation of grass species such as Kikuyu (Pennesitum clandestinum) was determined by observing the physiological attributes and colour.

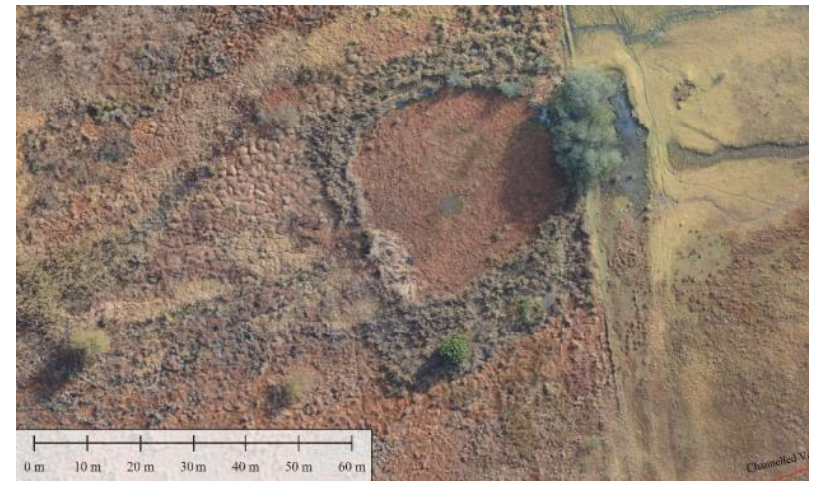

Figure 3. Estimation of disturbance classes from UAV orthophoto

The dry Kikuyu have a distinct colour in the winter (time of the UAV survey). The DPC (enabling the RGB colour) was also used for visualisation purposes, it provided the opportunity to visualise some of the reconstructed vegetation in 3D.

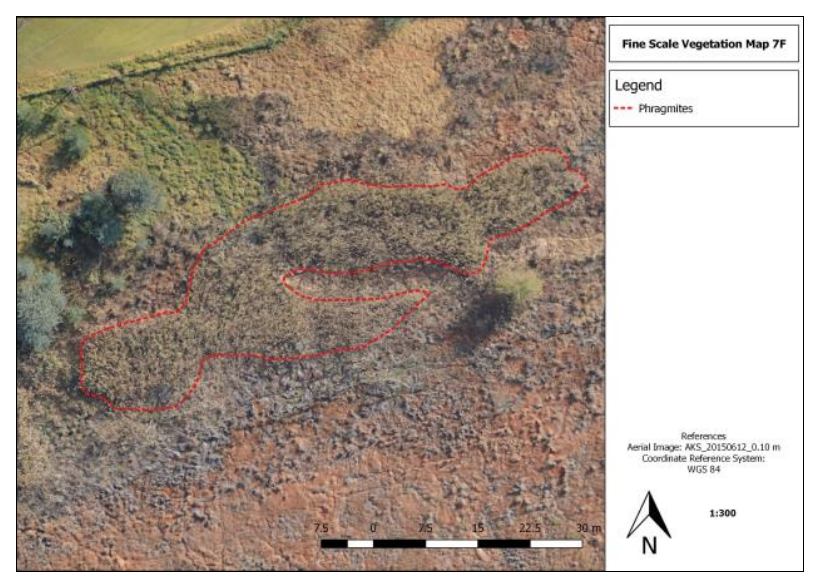

Figure 4. Extent of small pockets of untransformed hydrophilic vegetation

Further, grid intensity deviation was computed to visualise and analyse the point clouds. The computation was applied to the point cloud in real time for visualisation to provide answers in terms of the identification and estimation of the disturbance classes (Table 1) within the wetland and surrounding areas (Figure 5). Areas with a low deviation score 0-10 (orange to yellow/green) included areas which was subjected to anthropogenic disturbance. A deviation score of 11-25 (green) indicates areas with a medium disturbance. A score of 26-35 (light blue to blue) indicates intact wetland areas (limited disturbance) although one needs to note that in this score range (especially towards the end of this range), it also include alien tree stands such as black wattle which is also a disturbance class. This section is also interspersed with blue/purple and pink (3660) which represent mostly tall alien trees. Therefore it is important to visualise this calculations in combination with the UAV orthophotos. The two earthen dams with orange should also be ignored due to reconstruction errors of these two features (SfM algorithms did not found overlapping points mostly as a result of moving water). This information also informed the intensity and magnitude of impact for each disturbance class category (vegetation indicator 2) to inform the UAV vegetation assessment. 


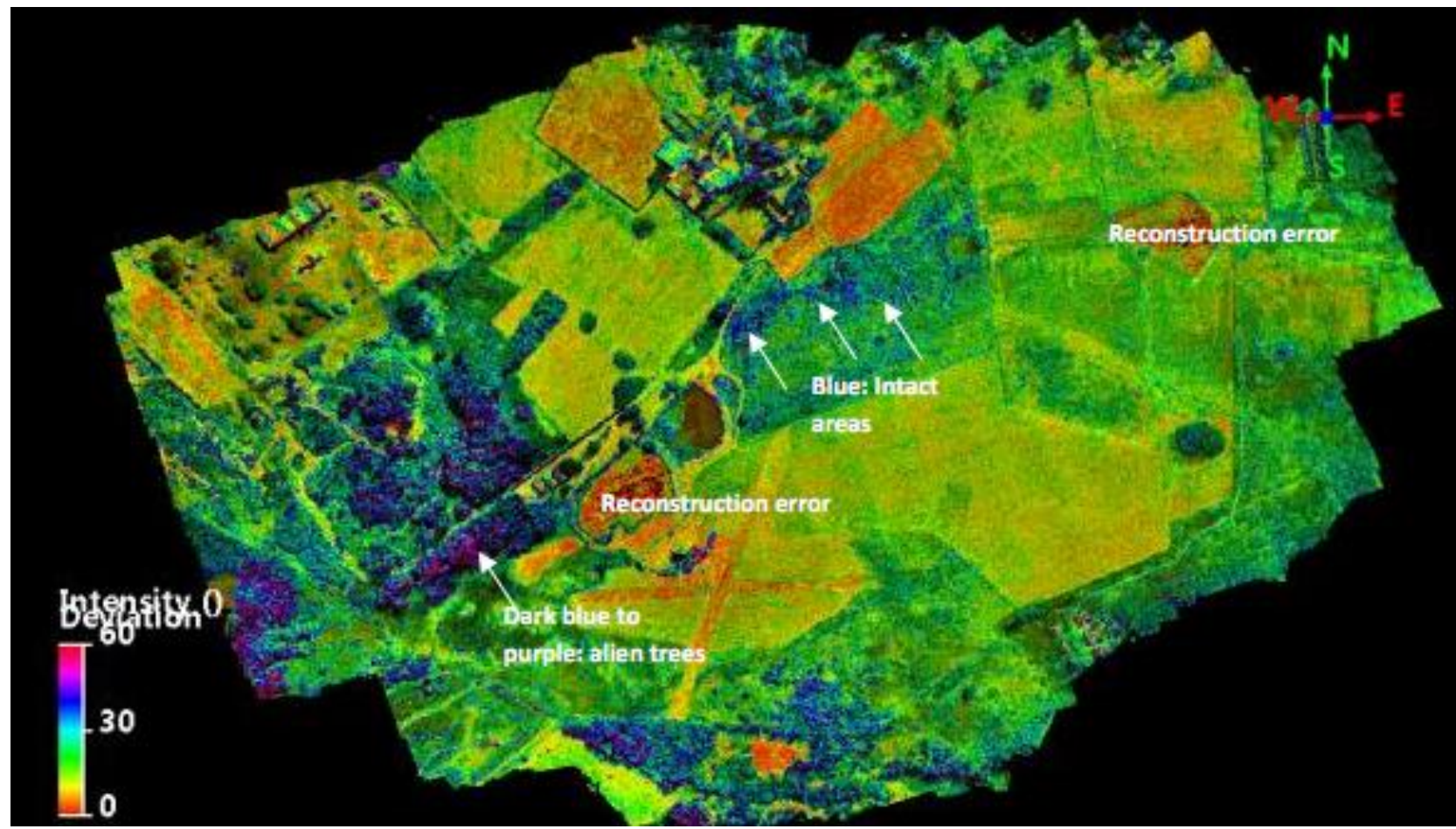

Figure 3. Intensity deviation calculation from DPC to identify and estimate the disturbance classes

The assessment using the UAV products reveals an increase of extent of all the disturbance classes from $\mathbf{4 5 . 7 \%}$ to $\mathbf{5 4 . 9 \%}$ and a slight increase of the intensity of impacts on vegetation integrity.

The WET-Health vegetation module completed with the aid of the UAV products still indicates that the vegetation of the wetland is largely modified ("D" PES Category) and that the vegetation of the wetland will further deteriorate (change score). However a higher impact score (activities taking place within the wetland) were determined (Table 3)

\begin{tabular}{|l|c|}
\hline $\begin{array}{l}\text { Present State of } \\
\text { Wetland/Riparian Vegetation }\end{array}$ & D \\
\hline $\begin{array}{l}\text { Trajectory of Change without } \\
\text { rehabilitation interventions. }\end{array}$ & $\downarrow$ \\
\hline $\begin{array}{l}\text { Detailed on-site evaluation of } \\
\text { vegetation Impact Score }\end{array}$ & 4.0 \\
\hline UAV Impact Score & 4.4 \\
\hline
\end{tabular}

Table 3. Vegetative Health of the system and trajectory of change.

\section{CONCLUSION}

The UAV products provided an accurate vantage point over the wetland and surroundings, and assisted to easily determine the vegetation state of the wetland. We conclude:

(i) The high resolution UAV imagery provided the opportunity to complete very fine scale extent determination and easy distinguish between the different disturbance classes and the intensity of impacts on the vegetation integrity. (ii) Grid statistics intensity deviation calculation of the DPC facilitated the extraction of important information to refine (map) the assessment of the vegetation disturbance classes of the wetland.

(iii) The extent of areas with untransformed wetland vegetation could be determined.

Valuable information is extracted from the UAV imagery and derived products that can enhance and facilitate better environmental planning and decision making. It is important to take note that the use of UAV imagery can and may not replace field studies but are an excellent tool if used in combination with field studies.

\section{ACKNOWLEDGEMENTS}

We would like to thank Aerial Kopter Solutions (AKS) and the RPAS Training Academy (PTY) Ltd who provided the equipment, resources and expertise to complete the surveying for this project. University of Johannesburg (UJ) Department of Geography, Environmental Management and Energy Studies for the use of their computer to process this dataset and for funding the conference attendance and the UJ Zoology Department that made it possible to undertake this research.

\section{REFERENCES}

Applied Imagery, 2015. Quick Terrain Modeller 8.0.5. Silver Spring, MD: Johns Hopkins Applied Physics Laboratory.

Anderson, K., and Gaston, K.J., 2013. Lightweight unmanned aerial vehicles will revolutionize spatial ecology. Frontiers in Ecology and the Environment 11(3),pp. 138-146. 
Boon, M.A., Greenfield, R. and Tesfamichael, S., 2016. Wetland Assessment using Unmanned Aerial Vehicle (UAV) Photogrammetry. International Archives of the Photogrammetry, Remote Sensing and Spatial Information Sciences, Prague, Czech Republic, Vol. XLI-B1, pp. 781-788.

Boon, M.A., Greenfield, R., and Tesfamichael, S., 2016. Unmanned Aerial Vehicle (UAV) photogrammetry produces accurate high-resolution orthophotos, point clouds and surface models for mapping wetlands. South African Journal of Geomatics, 5(2), pp. 186-200

Flener, C., Vaaja, M., Jaakkola, A., Krooks, A., Kaatinen, H., KukKo, A., Kasvi, E., Hyyppa, H., Hyyppa, J., and Alho, P., 2013. Seamless Mapping of River Channels at High Resolution Using Mobile LiDAR and UAV-Photography. Remote Sens.2013 (5), pp.:6382-6407.

Husson, E., Ecke, F., and Reese, H., 2016. Comparison of Manual Mapping and Automated Object-Based Image Analysis of Non-Submerged Aquatic Vegetation from VeryHigh-Resolution UAS Images. Remote Sensing, 8(9), 724

Husson, E., Reese, H., and Ecke, F., 2017. Combining Spectral Data and a DSM from UAS-Images for Improved Classification of Non-Submerged Aquatic Vegetation. Remote Sensing, 9(3), 247.

Lucieer, A., Turner, D., King, D., and Robinson, S., 2013. Using an Unmanned Aerial Vehicle (UAV) to capture microtopography of Antarctic moss beds. International Journal of Applied Earth Observation and Geoinformation, 27, pp. 53-62.

Macfarlane, D.M., Kotze, D.C., Ellery, W.N., Walters, D., Koopman, V., Goodman, P., and Goge, C., 2009. WET-Health: A technique for rapidly assessing wetland health.Water Research Commission, Pretoria. WRC Report No TT 340/09

Marcaccio, J., Markle, C., and Chow-Fraser, P., 2015. Unmanned aerial vehicles produces high-resolution, seasonallyrelevant imagery for classifying wetland vegetation. International Archives of the Photogrammetry, Remote Sensing and Spatial Information Sciences, Toronto, Canada, Vol. XL1/W4, pp. 249-256

Thamm, H.P., Menz, G., Becker, M., Kuria, D.N., Misana, S., and Kohn, D., 2013. The Use of UAS for Assessing Agricultural Systems in an Wetland in Tanzania in the Dryand Wet-season for Sustainable Agriculture and Providing Ground Truth for TERRA-SAR X Data. Archives of the Photogrammetry, Remote Sensing and Spatial Information Sciences, Rockstock, Germany Vol. XL-1/W2, 2013 UAVg2013, pp. 401-406.

Zweig, C.L., Burgess, M.A., Pecival, H.F., and Kitchens, W.M., 2015. Use of Unmanned Aircraft Systems to Delineate Fine- Scale Wetland Vegetation Communities. Wetlands, 35 , pp.303-309. 